\title{
Governance Through Learning: Making Corporate Social Responsibility in Dutch Industry Effective From a Sustainable Development Perspective
}

\author{
JACQUELINE CRAMER* \& ANNE LOEBER** \\ *Erasmus Centre for Sustainability and Management, Erasmus University Rotterdam, \\ The Netherlands \\ **Political Science Department/PERFORM, University of Amsterdam, Amsterdam, \\ The Netherlands
}

ABSTRACT An increasing number of firms try to implement corporate social responsibility (CSR) from the perspective of sustainable development. This article considers these efforts in the light of the changing relation between the state, society and the corporate sector, as a result of which governance increasingly takes the shape of a society-centred practice. The article focuses on stimulating governance through initiating learning processes among companies as a strategy for implementing CSR. It analyses the conditions under which learning may take place and may translate into action. To that end, it draws from the experiences of a comprehensive programme on CSR organized by the Dutch National Initiative for Sustainable Development (NIDO) which set out to accelerate transformation processes towards sustainable business by (i) facilitating learning among company representatives, (ii) assisting them to convey the insights gained to their respective companies, and (iii) influencing the contextual conditions that may incite companies to adopt CSR. The article argues that the ability to induce processes of learning and structural change renders the approach developed in the NIDO programme a viable contribution to realizing public policy ambitions by tapping into the dynamics of private organizations.

KEY WORDS: Governance, learning, corporate social responsibility, sustainable development

\section{Introduction}

Over the past two decades, the relation between state, society and the corporate sector has changed. The image of the state as a unified political space seems to be giving way to an appreciation of networks of state and non-state parties as the loci of political activity (Castells, 1996). Economic activity is tied ever more

Correspondence Address: Prof. dr. J. Cramer, Erasmus Centre for Sustainability and Management, Erasmus University Rotterdam, PO Box 1738, 3000 DR Rotterdam, The Netherlands. Fax: +3110-4089104; Tel.: +3110-4082050; Email: jmcramer@xs4all.nl 
closely to technological innovation and is organized in complex networks cutting across traditional boundaries. Obviously, states and private corporations in the past have joined forces in various ways to ensure the stability and prosperity of a nation's population and, most notably, of its workforce (Cannon, 1994). However, it is only now that the public-private distinction, which has long dominated the prevalent strains in political and economic thought in Western industrialized societies, appears to be losing terrain (Williamson, 1991).

An increasing number of firms make an effort to define for themselves a role as defender of public interests. A particularly observable trend is the redefining of the discourse on corporate social responsibility (CSR) in 'sustainability' terms. In this recent interpretation of CSR, the principles of corporate governance and management ('doing things right') and of corporate responsibility ('doing the right things') (cf. Zwetsloot, 2003) are redefined and integrated from the perspective of sustainable development. Among the growing group of companies that consider CSR a topical and useful way to pursue sustainability goals are the more than 160 firms who are members of the World Business Council for Sustainable Development (WBSCD). To the WBSCD, CSR is "the commitment of business to contribute to sustainable economic development, working with employees, their families, the local community and society at large to improve their quality of life" (Holme \& Watts, 2000).

For national governments, a 'sustainable' interpretation of CSR is obviously of relevance too. Most Western countries have adopted the notion of sustainable development as a central guideline in their national environmental policies (Beder, 1996). Struggling with the questions of what sustainable development may entail in a specific context, and of how to translate that into concrete policy measures, governments need companies to co-operate not only in implementing public policy ('co-production', Whitaker, 1980) but also in 'joint problem finding' (cf. Hisschemöller \& Hoppe, 1995-96). The pursuit of sustainable development requires new practices of public policy that cut across the market-state dichotomy. When the private sector voluntarily assumes responsibility for the social and environmental aspects of economic activities, beyond a mere meeting of regulatory demands, governance itself takes the shape of a society-centred practice.

The choice of interpreting corporate social responsibility from the perspective of sustainable development, however, is not without its problems. In addition to the exact nature of the relation between CSR and sustainable development ('what are the right things?'), corporations that commit themselves to such ambitions often wrestle with the question of how to implement CSR.

In the Netherlands, a programme was launched to support companies in their attempts to turn CSR into a business reality from a sustainable development perspective. The programme, called 'From Financial to Sustainable Profit', was organized by the Dutch National Initiative for Sustainable Development (NIDO), a publicly financed foundation that operated at arm's length of government.

NIDO was set up as a temporary organization with the purpose of structurally anchoring sustainable initiatives in society, and was in operation from 1999 to 2004. In order to realize its mission, NIDO co-ordinated dedicated 2-3 year programmes. The organization developed a 'learning approach' to managing transitions towards a more sustainable society (Loeber, 2003a). This approach, and the underlying choice to help realize public policy ambitions by tapping into the dynamics of private organizations, was unique (cf. Roome, 2002). 
This article focuses on the three-track strategy developed by NIDO in the programme on 'sustainable' corporate social responsibility. The article begins with a brief discussion of the sustainable development concept and of the reasons why and the ways in which it may have a bearing on CSR. Then, the NIDO programme on CSR is introduced. The next sections subsequently discuss the way in which learning processes on CSR were organized (i) among the individuals that took part in the programme, (ii) within the companies they represented and (iii) between these and other relevant parties (such as NGOs, the financial sector, governmental organizations). By relating in each section the NIDO experience to relevant literature, lessons are drawn on how to facilitate mutual learning as a strategy to implement CSR and to help create the conditions under which corporations are willing and able to do so. Thus, the NIDO experiment sheds light on how a public broker organization may assist the private sector in finding appropriate ways of contributing to sustainable development.

\section{Sustainable Development and Corporate Social Responsibility}

The concept of sustainable development was introduced in the realm of environmental thought in the early 1970s, when a special issue of the Ecologist magazine (later published as Goldsmith et al., 1972) addressed the urgency of designing "thoughtful, humane and measured changes" towards a society that "to all intents and purposes can be sustained indefinitely while giving optimum satisfaction to its members" (Goldsmith et al., 1972, pp. 1, 30). Like other 'limits-to-growth' representatives of those years (cf. Meadows et al., 1972), the issue's editors blamed industry, economic growth and technological development for environmental degradation. In the 30-odd years since, the concept's meaning has changed considerably (Achterberg, 1994).

\section{The Civil Corporation}

Contrary to the first-generation environmentalists, representatives of a second generation in environmentalism came to hold the idea that environmental protection is not necessarily opposed to economic development. The notion of sustainable development was coined to indicate a process of increasing productivity which does not deprive future generations of the use of natural resources (IUCN, UNEP \& WWF, 1980; WCED, 1987). In its authoritative report, Our Common Future, the World Commission on Environment and Development used Goldsmith et al.'s terminology to describe the desirability of a process of change, in which "the exploitation of resources, the direction of investments, the orientation of technological development and institutional change are all in harmony and enhance both current and future potential to meet human needs and aspirations" (WCED, 1987, pp. 9, 46).

The discarding of the 'zero-sum trade-off' interpretation of the relation between economic and environmental goals cleared the path for corporations to potentially play a role in the attainment of sustainable development. The opportunities created by the 'rolling back of the state' (Cannon, 1994) added to the potentiality for business to take on new responsibilities in this respect. Furthermore, NGOs, rapidly increasing in number (Zadek, 2001, p. 80), and citizens, alienated from the traditional political arrangements (Cramer, 2002), increasingly 
called upon individual firms and international institutions to subject to public scrutiny decisions that may have public consequences.

The reasons for firms to actually do so are manifold. Zadek (2001, pp. 65-71) groups the varieties of considerations into four broad, interrelated categories: defence-such as the wish for damage repair in view of loss of credibility among the public, for example due to NGO media campaigns; the traditional business case - referring to the ambition of financial gain, such as through uplifting the working or living conditions of a company's workforce or via improved resource management and waste reduction; the strategic business case-involving the acknowledgement that fundamental changes in a company's core processes (such as a shift from non-renewable to renewable resources) may help guarantee the firm's long-term business performance; and what Zadek calls learning, innovation and risk management-entailing the acknowledgement that successful businesses are those that are able to effectively innovate their processes, products and services, knowing how to respond to new forms of risk, how to translate information about stakeholder interests into new business and so on.

While all of these types of motivation may be captured under the heading of 'enlightened self-interest' (Cannon, 1994, p. 39), over the last two decades, the level of ambition for corporations in general to assume responsibility for affairs other than wealth creation appears to be rising. Zadek (2001, pp. 73-76) distinguishes between 'three generations' of CSR ('corporate citizenship'), the first of which merely sought to be responsible in a way that does not detract from business, whereas the latest poses the question whether "corporate citizenship is likely to be significant in addressing growing levels of poverty, exclusion and environmental degradation" (2001, p. 74). In that latter interpretation, CSR embraces a sustainability agenda.

The corporate governance debate has evolved from a focus on the organizational aspects of management accountability in the1990s to a situation in which CSR is considered to converge with the ambitions of sustainable development (as it is in the aforementioned WBSCD definition, a definition adopted in the remainder of this article). With rising levels of aspiration (and expectation!) regarding the role of business in society, the questions of what exactly may be considered an appropriate elaboration of CSR and of how that can be established and implemented become all the more pressing.

Business has no democratic mandate to legitimize the political judgments involved; for this reason, some authors question the desirability of companies to take on tasks other than strictly commercial ones (Cannon, 1994). ${ }^{1}$ However, governmental organizations-with such a mandate-nowadays turn explicitly to the corporate sector (and other non-governmental parties) to take up the issue. Corporations are expected to be 'civil': to take full advantage of opportunities for learning and action in building social and environmental objectives into their core business (Zadek, 2001). The developments in the Netherlands are illustrative, when Prime Minister Kok called publicly upon business firms and societal organizations to develop "a more structured approach" to organizing and implementing CSR in the Dutch society (Kok, 2001).

\section{CSR in the Netherlands}

The issue of CSR from a sustainable development perspective ('sustainable business') appeared on the political agenda in the Netherlands in the late 1990s. 
In a first reaction, the Dutch government turned to its main advisory body on matters of national and international social and economic policy, the Social and Economic Council (SER). The SER's advice (2001), prepared by the council's experts in close consultation with representatives of employers' organizations and trade unions, came to the conclusion that CSR is a crucial aspect of the core business of any enterprise, and that responsibility for its implementation therefore rested with companies. The Council expected public awareness on the issue to provide sufficient incentives to incite companies to take their responsibility seriously. The government was advised not to take regulatory steps on the issue at the time.

Indeed, international and national stakeholder pressure was increasing. The Council's advice itself triggered NGOs in the Netherlands to formulate more explicitly their own position in the debate. A number of NGOs bundled their forces and prepared an agreement on what the organizations considered quintessential in propagating CSR. The main consumers' organization, the Consumentenbond, decided to inform its members systematically about environmental and social aspects of consumer products, in addition to its regular product information; a decision that was made effective in 2003 with the publication of a 'black list' of companies that failed to provide requested information on such aspects as child labour, animal welfare and the environmental impacts of their product range. These developments formed the backdrop against which the NIDO programme on CSR was organized.

\section{'From Financial to Sustainable Profit'}

The programme on CSR, 'From Financial to Sustainable Profit', was NIDO's first major activity. The objective of the programme was to initiate and support processes of change among companies wishing to create a link between their financial performance and their record in ecological and social matters (Cramer, 2001).

The programme ran from May 2000 until December 2002 and focused on the interface between the 19 participating companies and their stakeholders. Two projects were carried out within the programme: (1) implementing CSR in business practices and (2) marketing-communication about CSR (Cramer, 2003). NIDO organized monthly meetings of four hours each for both project groups in order to exchange experiences with making CSR effective in business practice, to discuss common problems and to interact with external stakeholders. Moreover, every company carried out a specific in-house project on the issue during the period January 2001-July 2002. These projects were discussed and reflected upon in the programme's meetings. The meetings' discussions and conclusions were documented in extensive minutes. The programme manager visited the participating firms every five months to keep track of the progress made.

In addition to co-ordinating both project groups, NIDO participated in various initiatives concerning CSR, in order to reinforce mutually the NIDO programme and these initiatives. Special attention was paid by NIDO to the strengthening of the knowledge infrastructure in the field of sustainable business. The participating companies and NIDO itself took care of dissemination of the results of the programme to other companies and to society at large, through conferences, media exposure and publications (among them Cramer, 2003). 


\section{A Three-Track Strategy to Facilitate Learning and Action on CSR}

The NIDO programme set out to achieve its mission by stimulating companies to continue and accelerate the processes of transformation towards more 'sustainable' business in which they had already engaged. To that end, a three-track strategy was outlined.

First, the programme set out to facilitate learning among the representatives of the companies that participated. ${ }^{2}$ An approach to learning was adopted that was reminiscent of Revans' $(1980,1982)$ 'action learning': a group of professionals came together on a regular basis to help each other reflect on real, workplacerelated problems. The monthly meetings were organized to provide a supportive environment for all to engage in processes of mutual learning. No clear-cut answers were presented there. Yet, as the participating firms' CSR orientation varied from 'First Generation' to 'Third Generation' interpretations, in Zadek's terms (2001, p. 75, see above), the participants could profit from one another's insights and experience. Moreover, the unfamiliar setting and 'unusual' discussion partners (the 19 participating firms represented wide varieties of sectors, ranging from chemical industry to banking) placed participants outside their 'comfort zone' and could thus stimulate them to take a fresh look at the issues discussed, and to engage in critical self-reflection.

Notably, the latter aspect of learning was considered of relevance for CSR. After all, implementation of CSR may well involve changes that are inspired by so-called first-order learning ("single loop learning", Argyris \& Schön, 1996). A company's efforts to improve its production process technically in terms of environmental standards provide a case in point. However, in the encompassing, 'sustainable development' perspective adopted in the programme, CSR is not merely a question of incorporating its practical implications within a company's existing operating practices, policy principles and standards. Rather, it requires a critical review of a company's fundamental values, policy principles and operational procedures. The review of theories, values and assumptions, and even of the underlying beliefs and world-views entails so-called second-order learning ('double loop learning') and may result in major changes in a company's strategic choices, objectives and preferences. A shift from a First or Second Generation understanding of CSR towards a Third Generation interpretation arguably involves second-order learning.

Second-order learning requires a degree of self-reflection that is hard to achieve of one's own accord. It may occur when a person is no longer able to 'shut out' dissonant information (for instance when others explicitly direct a person's attention to "what he has worked to avoid seeing"; Schön, 1983, p. 283) or when one deliberately wishes to reflect on one's professional practice. A setting in which defence mechanisms (Argyris, 1990) are dismantled and one is stimulated by others to take into consideration new and possibly counterintuitive information may therefore encourage and accelerate the learning event. The NIDO programme intended to deliberately create the conditions under which second-order learning could take place (Loeber, 2003b).

The second track in the NIDO strategy was to assist strategically and practically the representatives participating in the meetings with translating the insights gained to the practice of their respective companies. Integration of environmental, health and safety programmes into corporate business is known to be notoriously problematic (cf. A.D. Little, 1995). Shelton (1994), who claims that there exists 
a credibility gap between environmental management and business management, speaks of a 'Green Wall' that may stall progress towards a greening of the boardroom. Among other reasons, this is due to poor communication between the two. The 'Green Wall' literature suggests that business managers often regard CSR in terms of 'defence' considerations (keeping a company out of juridical or reputation trouble) while environmental managers often recognize its strategic advantages (in view of a company's 'licence to operate', of guaranteeing material supplies in the long run, of risk management and so on). The NIDO programme sought to assist in breaking down the 'Green Wall' and to help firms develop an integrated approach to CSR - a process understood in terms of (second-order) learning at company level.

Learning may be a necessary, yet not a sufficient, precondition for change. A corporation's willingness and ability to redirect its mode of operation in the light of newly developed views critically depends, next to its resources, on regulatory and societal pressure, e.g. from NGOs ("civil regulators"; Zadek, 2001, p. 56) and the stimulating and enabling qualities of a firm's wider structural setting (juridical, physical infrastructure, economic and social conventions and so on) in which it operates. A third track in the NIDO strategy, therefore, was to influence the contextual forces that may affect firms' CSR strategies and initiatives. Although the context's parameters may seem fixed to the individual, the rules, conventions and physical structures that moderate and guide a firm's actions are themselves being produced and reproduced through the acts of individuals and organizations (cf. Giddens, 1984). Wilful structural change, hence, is possible by acknowledging that what appears a given, limiting condition for one, is the outcome of purposeful actions of others. NIDO set out to modulate activities of third parties in line with the findings from the programme, selecting relevant parties on the basis of the questions and needs expressed by the participating firms.

\section{Conceptual Elaboration of CSR}

The programme adopted a process-orientated approach to dealing with the corporate social responsibility issue. The programme took Elkington's (1997) broad interpretation of CSR as "managing the triple bottom line" as a general point of departure. Understood in these terms, CSR involves the challenge of finding a responsible balance between People ('social well-being'), Planet ('ecological quality') and Profit ('economic prosperity'), and of translating that into a comprehensive and integrated approach to doing business, across the entire organization.

Because of the action learning approach adopted in the programme, no clearcut results could be formulated in advance. Over time, the company representatives that participated in the monthly meetings elaborated the Triple-P concept on the basis of their own experiences, exchanging views and opinions with one another and with representatives of 'third parties' (consultancies, NGOs, the financial sector, governmental organizations, universities, media). In the course of the programme, each participant to a greater or lesser extent revised his or her views on the subject and gained practical insights on the implementation of CSR that were appropriate for, and applicable to his or her own company and context. ${ }^{3}$ In addition, some general conclusions were drawn, which were shared by all involved. 
A general conclusion from the programme was that implementing CSR requires 'double-edged' action: it involves reflection on a company's core values and the way these may be translated into practical procedures, and it involves practically reorienting and reorganizing operational procedures at the level of business units while seeking ways to gain Board commitment for these changes. The participants argued that it is not a matter of 'either/or': when approaching the theme from a pragmatic perspective, one should be well aware of the fact that CSR is not merely a procedural exercise of adding complementary paragraphs to the existing quality control systems. When approaching the issue from the perspective of changing a company's core values, one must realize that the required 'paradigm shift' cannot be brought about by discussing it in an abstract manner.

\section{Creating the Conditions for Learning at Group Level}

At the monthly meetings, the participants shared with one another the insights that they had gained from their own experiences hitherto, and from implementing the in-house projects that they had formulated in the context of the NIDO programme. Furthermore, during some of these meetings, discussions with varieties of stakeholders were arranged. The meetings were intended to serve as a clearing house of information and, at the same time, to trigger processes of learning on the part of the participants. An evaluation of the programme showed that these objectives had been met successfully (Loeber, 2003b).

What the participants learned exactly at an individual level varied widely, depending on the stage of development of CSR within their organization, the company's culture and on their personal interests and characteristics. An analysis of their utterances reveals that on the whole, the 'inspiration' that they reportedly gained from participating amounted to first-order learning and, in some cases, to second-order learning. Most participants put an emphasis on getting CSR off the ground in their respective companies by introducing measures that sat well with the company's regular routines. Some were also interested in exploring the fundamental principles behind corporate social responsibility. They began to question their company's way of thinking and acting, and viewed the adoption of CSR as a 'paradigm shift'. The evaluation made clear which methodological and organizational aspects of the programme rendered it particularly conducive to learning.

\section{Group Composition}

The firms that participated in the NIDO programme differed largely in size and type. Both small and medium-sized companies and multinationals were involved, representing a variety of sectors. Also the representatives taking part varied in their respective institutional position and power. What the participating company representatives held in common was a general sense of urgency with respect to the need of implementing CSR, and some reservoir of experiences with such implementation at the time of their joining the NIDO programme.

The large differences among the participating companies were not seen as a barrier for the exchange of relevant information. On the contrary, group composition turned out to be a major force in triggering learning, as the participants got new information from unexpected sources and, more importantly, got 
familiar information reviewed from unexpected angles. A senior manager of a multinational operating in a business-to-business market reported, for instance, that he was inspired by the stories of representatives of consumer-orientated companies on 'how to get started'. The experience of these colleagues was that it pays to get started with small but concrete sub-projects, thus creating a head start for a more fundamental and far-reaching re-orientation within the company. From this, he came to the conclusion that adoption of CSR by his company might well be realized by "linking the concept to our standing procedure for formulating our business strategy", which included project-like activities of self-evaluation, discussion and reflection that took place in every business unit on a three-yearly basis.

\section{The Role of the Programme Manager}

Another characteristic that turned the process into 'a learning experience' in the eyes of the participants was the way in which it was chaired by the programme manager. In line with the overall role that the NIDO organization had chosen to adopt, the programme manager operated as moderator between the individual change agents who attended the NIDO meetings and their contexts (the firms they represented and the firms' wider institutional setting).

In addition to this moderating function, the programme manager adopted a facilitating role at the meetings, enabling the participants to determine jointly the contents of the discussions as well as the course of the process, and to reflect on their own and each others' utterances. Characteristically, a project's group meeting ended with the programme manager going over the core elements of the discussion, regularly checking her interpretation with that of the participants. From this summary, she then drew conclusions about which topics seemed to require further discussion and proposed a suitable procedure (by inviting a guest speaker, commissioning additional research, by making use of external facilitators who employed specific discussion techniques, and so on). At the same time, the programme manager ascertained the inferences made were consistent with the conclusions drawn at previous meetings and evolved into a coherent understanding of implementing CSR in the face of diversity.

This approach to chairing the meetings, which was dubbed 'servant leadership' by some, was highly appreciated by the participants. It ensured that the topics elaborated within the programme reflected closely the interests and concerns of those around the table, and that the lessons drawn on implementing CSR were sufficiently context-specific to be of relevance to the participating firms.

\section{Emergent Programme Design}

The responsive focus of the programme was coupled to a procedural flexibility that allowed for an exploratory approach to specifying CSR. While presented as a programme on 'sustainable profit' the question as to what that meant exactly was left completely open at the time the participants were invited to join. Nowhere in the initial project plans was the topic defined beyond Elkington's general Triple-P understanding. This was a deliberate choice. The discussions thus focused on issues that were raised by the companies themselves and related to specific knowledge gaps or problems that they had encountered in implementing CSR. Because the outcome of any one meeting determined both the selection of discussion topics and the approach used to address them in the 
next meeting, the NIDO programme was characterized by an 'emergent design'. Due to this design and the programme manager's facilitating role, the NIDO programme produced insights which, put together, went well beyond the sum of individual inputs, including those of the programme manager. As one of the participants put it: "essentially, NIDO was an induction process in which the particular-that is, events seen in the specific contexts of the participants, provided the basis for generating more general yet still practical ideas and insights on CSR".

\section{Reciprocity and Trust}

In spite of their differences, the participants found that they were bound by a shared struggle of getting their views and ideas accepted within their respective companies. As one of the participants put it, it was "reassuring just to hear that others are tearing their hair out as well". This remark is illustrative for the atmosphere of trust that was created within the programme setting. Professionals who in their everyday context were trained and conditioned to emphasize success and to keep doubts to themselves, felt at liberty to speak freely at the meetings about their worries and failures.

Concrete agreements on the confidentiality of the meetings' contents and minutes, group composition ("had there been firms from the same market segment, we would probably just have been watching one another"), consistency in group composition (there was little change in the actual persons present during the course of the programme), the open and inviting attitude of the programme manager, and the implicit 'rule' of reciprocity ('I open up if you open up') all contributed to the creation of trust. As a result, the programme was more than an opportunity to learn from others in a similar situation; it provided a setting in which participants were induced to reflect on their interpretative frame (cf. Schön, 1983) and, where thought necessary, to revise their practical understanding of CSR (first-order learning) or the underlying theories and assumptions (secondorder learning).

The relevance of this programme characteristic is illustrated by the tepid reception of the specialist expertise provided by the occasional guest speaker. Typically, a guest speaker's input was evaluated afterwards. With the exception of one, all presentations were considered to be of minor importance. This was due partly to the general tone in which most information was voiced, as a result of which it seldom 'struck home'. The indifference, however, was caused too by the lack of reciprocity the speakers displayed, which was at odds with the group's culture. Notably the commercially based consultants had little interest in sharing what they saw as their kitchen secrets. For fear of losing their intellectual capital (and perhaps of losing face), they declined to discuss in depth the assumptions and theories that underlay the information they offered. The reluctance to 'speak their minds' in the eyes of the participants detracted from the message the guest speakers meant to convey.

\section{Reflection In and On Action}

Merely talking about a proper balance between People, Planet and Profit was considered by the participants to be insufficient to deepen the understanding of what implementing CSR might entail in the context of a specific company. For them, running their own project and discussing it at the monthly NIDO meetings 
provided a fruitful mix of action and reflection. The 'lived' experience, in combination with a structured exchange of information about it, enabled them to improve the concrete strategies they employed and induced them to question consciously and constantly the management theories and normative considerations underlying these. In addition, participation in the NIDO programme proved useful in keeping a check on the progress made in the projects.

\section{Creating the Conditions for Learning at Company Level}

The company representatives involved in the NIDO programme had a difficult task. They acted as the intermediaries between NIDO's learning group context and their own companies. The challenge was to transfer the knowledge and experiences gained in the NIDO group to their own organization and, moreover, to encourage second-order learning processes required for a genuine shift to (Third Generation) CSR. The NIDO programme proved instrumental to some extent in dealing with the transfer difficulties and breaking down the 'Green Wall': (i) the programme gave 'status' and momentum to the activities of the participating company representative, which was helpful in gaining the support and co-operation of key people within one's organization; (ii) the programme manager's visits to the participating companies reinforced the urgency to take CSR seriously among higher management; and (iii) the programme helped accumulate and share ideas and experiences on how to proceed. The main findings on the subject are listed in the following sections.

\section{Putting CSR on the Agenda Throughout the Company}

At the onset of the NIDO programme, a zero-assessment of the CSR performance of each of the participating companies was made. This was done with the aid of a 'Sustainability Score Card', a list of questions related to the People, Planet and Profit aspects of a business, together with a rating of the answers. The Score Card exercise proved instrumental in putting CSR on the agenda of the participating companies' divisions and business units. It required the collection of information from a variety of departments, drawing the attention of staff at all levels throughout the organization to CSR in general, and to the NIDO exercise in particular. A request for information was often followed by a discussion on what CSR meant and why the company would focus on it. Moreover, having been asked for information in view of a 'Sustainability' Score Card made people aware of the link between their job and CSR.

\section{Anchoring CSR in the Organization}

The Score Card exercise in many cases helped identify relevant discussion partners and potential project team members. Team composition was found to be of great importance. Close collaboration between what are usually rather disparate departments was considered to be desirable. Furthermore, it was seen to pay to include in the CSR project team a diversity of people, not only with respect to their disciplinary expertise, but also in terms of their personality. As one participant put it, the successful adoption of CSR in his company was explained mainly because his team included "a creative thinker, a fighter, an implementer, and someone with exceptional communication skills". 
The timely installation of a CSR project team was found to be crucial too. The experience of the 19 NIDO participants showed that those companies in which the formation of a project team preceded the preparations of the in-house project formulated in the NIDO context were generally more successful in implementing their plans than those where no such project team was yet in place. In those cases, the subsequent CSR action plans were often received poorly (the 'not invented here syndrome').

A progressive elaboration and subsequent adoption of CSR, it was found, can benefit greatly from integrating additional processes of data collection (for instance, for issuing an annual social report) into existing information flows. Anchoring CSR in existing monitoring and reporting management systems results in cost reduction, increases acceptance and provides stability for CSR activities to withstand spells of economic or organizational bad weather. Without such an anchorage, as several of the participants experienced in the course of the NIDO programme, apparent support for CSR may, under unfavourable conditions, disappear almost overnight.

\section{Ensuring Commitment From the Board of Management}

Although all participating firms had signed a declaration of consent in advance, the company representatives in the NIDO programme could be divided roughly into two categories: those who had full commitment from their Board of Management, and those who lacked actual support. When concrete action was required, the Board's commitment turned out to be only skin deep. A oneoff signature to indicate approval of a future project on CSR, it was found, is not enough.

Useful strategies developed by the NIDO participants to sustain initial support and to bridge the 'credibility gap' included: (i) ensuring (informal) personal involvement of Board members in the CSR project planning process; (ii) insisting that the Board would substantiate its commitment with a written statement on the reasons why the company should take its social responsibility seriously; and (iii) explicating and formalizing existing implicit rules and procedures under the heading of CSR. Aspects of CSR that are inherent in a company's culture and heritage often go unnoticed, notably with respect to the social dimensions of a firm's activities. Spelling these out may be useful in communicating a company's profile, and in showing the Board and others that adoption of CSR is not a giant leap away from the ordinary; and (iv) making CSR a business proposition (attracting qualified staff, reducing damage-compensation costs, and so on; cf. Shelton, 1994). Detailing the added value of CSR in financial terms was found useful, especially by those who did not share the 'passion' for CSR that some of the participants reportedly experienced, and for those whose companies typically embraced a First Generation approach to CSR.

\section{Using 'First-Order' Information to Stimulate 'Second-Order' Shifts}

The NIDO participants found that in-house communication on CSR was facilitated by translating the abstract concept into down-to-earth activities. Well aware that company culture is usually hands-on and orientated towards concrete action, they were thus able to motivate their colleagues to join the effort. 'First-order' information often corresponded well with existing practices, policy statements 
and standards of a company. As a result, the learning that was seen to take place in the companies at first glance amounted to mainly first-order learning. However, the renewal processes that the change agents elicited were more fundamental than they seemed to be on the surface. Discussions of a firm's communication strategies, for example, were in fact catalysing a new positioning of the company vis-à-vis society at large, and its stakeholders in particular. Although this kind of discussion might not immediately set forth visible changes in a company's course, it could contribute over time to a fundamental change in the mindset of the key figures in the organization.

\section{Targeting the Appropriate Level in the Appropriate Way}

Since in-house communication on CSR is often problematic, the NIDO participants considered that it pays to direct the efforts carefully to the appropriate addressees. In this respect, the 'Green Wall' rhetorical dichotomy between environmental management and business management needs refining: a focus on 'reformulating a company's current mission statement and CSR orientation' requires the active involvement of the Board of Management; 'implementing a code of conduct' requires involvement of middle management especially; the 'development of an action plan for CSR' requires an exchange of views between the Board of Management and middle management; and the 'actual implementation of specific actions' affects staff at all levels in the organization and hence requires an inclusive communication strategy.

The individual change agents' efforts to implement CSR through tailor-made strategies-designed on the basis of the perceived level of receptivity in the organization and his or her own interests, organizational position and sphere of influence-were backed by the NIDO programme manager's visits to discuss findings and progress with selected senior staff.

\section{Influencing Contextual Factors}

In order to contribute to the companies' ability and willingness to act upon the insights gained, the programme manager initiated contacts with relevant third parties to discuss CSR, to learn about their activities on the theme and to convey the views of the companies participating in the NIDO programme. In this way, the NIDO programme sought to ensure their input into on-going CSRrelated developments. Thus, the programme built bridges between groups who generally did not meet to discuss CSR in a general manner as a topic of common interest.

The programme took the firms' specific barriers to change towards an integrated CSR approach (identified in the monthly meetings and through the implementation of the in-house project) as a point of departure in engaging in the discussions with stakeholder groups. These groups were selected from the expectation that they were in a position to 'even out' these barriers or to contribute actively to the creation of favourable conditions for implementing CSR.

The programme, for example, made an effort to help structure the formal knowledge-generation process on CSR within academia. The general public's call upon firms to accept their social responsibility had left much of the private sector in need of an operational understanding of what 'good entrepreneurship' in this respect might entail and of tools and instruments to translate this 
understanding into business. The topic had caught the eye of various knowledge institutes that initiated research programmes on these and related questions. The NIDO programme established fine-tuning between academic knowledge producers and potential corporate knowledge users. First, NIDO got the majority of issue-related researchers in the Netherlands to sit together and present their respective research to each other (which presented a unique occasion for discussion on CSR in the academic world). Secondly, an inventory was made of the research needs of the companies that participated in the NIDO programme. This eventually resulted in the drafting of a joint research proposal between seven universities. The proposal, and the willingness of private partners to participate in the programme, was convincing to the Ministry of Economic Affairs to such an extent that it agreed to support the research programme financially for an initial period of two years. As a spin-off of the NIDO initiative, several of the NIDO participants were enlisted, so to speak, as a semi-permanent forum to comment on the research programme's plans, activities and findings.

The NIDO programme played a similar mediating role in the exchange of information between the financial sector and business firms. As early as the 1990s, the financial sector had started with sustainability investment funds. Since the start of the present century, practically every bank had incorporated such funds in their regular package of investment products. Banks had expanded their own research capacity and/or sought the assistance of specialized rating agencies to benchmark company performance on 'People, Planet and Profit' aspects. To business firms, this development provided additional chances to present and accentuate their profile (for example, as a 'green industry'). Yet, it also implied an additional workload and increased uncertainty. Different banks requested different sets of data from firms, which often were very time-consuming to provide while the surplus value of the effort was not at all clear. By the time the NIDO programme was conducted, the banks and investment organizations had joined forces in an attempt to standardize information-collecting efforts. The NIDO programme contributed to these activities by organizing an exchange of information between representatives of the financial sector and the companies that participated in the programme.

Another example of bringing in alignment the needs and interests of the business community with those of its 'contextual' parties was NIDO's input in the work of the Council for Annual Reporting. The Council formulates, on request of the national government, the non-binding yet coercive guidelines by which companies organize their annual financial reporting. At about the time of the start of the NIDO programme, the Council was asked to draft guidelines for reporting information on corporate environmental and social performance as well. To the business community, such guidelines may provide a strong incentive to focus on efforts in these spheres. Through the mediation of NIDO, the experience with CSR that was gained by the companies that participated in the programme was made available to the Council, and made a valuable input into the process of drafting guidelines.

NIDO also stimulated the awareness of CSR among branch-organizations as well as among local governments. Discussions with representatives of various municipalities and provinces were held to define their role in stimulating CSR in industry and within their own governmental organization.

The inputs that the companies through their participation in the NIDO programme could provide to the activities of these and other relevant parties thus 
potentially contributed to the development of structural conditions that were favourable to their CSR-initiatives. In turn, because of the exchange of information between them and various echelons in society, companies had an opportunity to learn about (forthcoming) developments that might affect their context in the future. Thus, they were able to assess the relative importance of these developments for their mode of operation. The meetings that NIDO organized with the NGOs in particular appear to have been useful in that particular way.

\section{Conclusions}

The ambition of attaining sustainable development puts demands on the corporate sector. Corporations are pressed to assume responsibility for the social and environmental aspects of their business operations, beyond a mere meeting of regulatory demands. Corporate social responsibility (CSR) as a particular interpretation of corporate governance offers a useful and topical way for firms to tackle environmental and social problems associated with economic development. The NIDO programme on CSR assisted companies to shift their attention from focusing solely on their financial performance to including their ecological and social performance, and to help them embed environmental and social considerations into core business systems.

Implementing CSR, the NIDO experience showed, is a complicated and, at times, frustrating process of designing tailor-made solutions that match the specific characteristics, ambition levels and the socio-economic context of a company. On a practical level, NIDO's initiative provided a meaningful contribution to the ability of firms not only to further their ideas on what CSR might entail, but also to practically act in line with that understanding. By creating a transient institutional setting to explore the meaning of CSR discursively, it offered an opportunity for its implementation without imposing an a priori formulated definition of the concept. By attuning the learning experiences to the practices of key societal actors, furthermore, the NIDO programme strengthened and arguably accelerated current developments towards more 'sustainable' business. On a conceptual level, the experiment contributed to the understanding of the role of first-order and second-order learning in implementing CSR, and of the methodological and practical conditions under which such learning may be induced and may translate into corporate action.

Thus, the NIDO initiative showed how a public broker organization may play a successful role in the realization of public policy ambitions by tapping into the dynamics of private organizations. Experiments like this can help develop an understanding of governance as a society-centred practice, with a key role for mutual learning, in view of aspiring sustainable development.

\section{Notes}

1. Cannon (1994, p. 37) refers to various publications from the 1960s and early 1970s to make this point, among them Friedman who is quoted at some length: "If businessmen do have a social responsibility other than making maximum profits for their shareholders, how are they to know what it is? Can self selected individuals decide what the social interest is?" (Friedman, 1962). Of course, conceptual thought on the relation between state, society and corporate sector has changed fundamentally since.

2. Ideas on CSR and on organizational learning are often articulated in one breath. As the concept of learning is used to cover "a wide society of ideas" (Minsky, 1988, p. 120), it is useful to examine 
closely the meaning of the concept as it is used here. In many publications on CSR/sustainable development and (organizational) learning (e.g. Molnar \& Mulvihill, 2003; Senge et al., 1999; Zadek, 2001), learning is discussed as a goal in itself, and the "development of an organizational learning culture" as a major precondition for fostering "sustainable enterprises" (Molnar \& Mulvihill, 2003, p. 168). In the NIDO programme, in contrast, learning was considered as a means, as a strategy to implement CSR, by facilitating simultaneously the production of knowledge on what to do, and on how to do it (cf. Loeber, 2004).

3. The data in the research that is described here were collected through document analysis and via participant observation of most of the monthly meetings during the course of the NIDO programme, and through interviews with its participants after the programme had come to a close.

\section{References}

Achterberg, W. (1994) Samenleving, Natuur en Duurzaamheid (Assen: Van Gorcum).

Little, A.D. (1995) Hitting the Green Wall (Cambridge, MA: Arthur D. Little).

Argyris, C. (1990) Overcoming Organisational Defences-Facilitating organisational learning (Needham Heights: Allyn and Bacon).

Argyris, C. \& Schön, D. (1996) Organisational Learning II; Theory, Method, and Practice (Reading, MA: Addison-Wesley Publishing Company).

Beder, Sh. (1996) The Nature of Sustainable Development (Newham, Australia: Scribe Publications).

Cannon, T. (1994) Corporate Responsibility. A Textbook on Business Ethics, Governance, Environment: Roles and Responsibilities (London: Pitman Publishing).

Castells, M. (1996) The Information Age: Economy, Society and Culture. Volume I. The Rise of the Network Society (Malden, MA: Blackwell Publishers).

Cramer, J. (2001) From Financial to Sustainable Profit; Programme Plan (Leeuwarden: National Initiative for Sustainable Development).

Cramer, J. (2002) From Financial to Sustainable Profit, Corporate Social Responsibility and Environmental Management, 9(2), pp. 99-106.

Cramer, J. (Ed.) (2003). Learning about Corporate Social Responsibility; The Dutch experience (Amsterdam: IOS press).

Elkington, J. (1997) Cannibals with Forks; the Triple Bottom Line of $21^{\text {st }}$ Century Business (Oxford: Capstone).

Giddens, A. (1984) The constitution of society: outline of the theory of structuration (Berkeley: University of California Press).

Goldsmith, ? et al. (editors of The Ecologist) (1972) A Blueprint for Survival (Harmondsworth: Penguin Books).

Hisschemöller, M. \& Hoppe, R. (1995-96) Coping with Intractable Controversies: The Case for Problem Structuring in Policy Design and Analysis, Knowledge and Policy: The International Journal of Knowledge Transfer and Utilization, 8(4), pp. 40-60.

Holme, R. \& Watts, P. (2000) Corporate Social Responsibility: Making Good Business Sense (Geneva: World Business Council for Sustainable Development).

IUCN, UNEP \& WWF (1980) World Conservation Strategy: Living Resource Conservation for Sustainable Development (Morges, Switzerland: IUCN).

Kok, W. (2001) 'Samenleven met ondernemingen', Raiffeisen lecture: Den Haag, April 2.

Loeber, A. (2003a) Inbreken in het Gangbare. Transitiemanagement in de praktijk: de NIDO benadering (Leeuwarden: NIDO).

Loeber, A. (2003b) Learning processes at group level, in: J. Cramer (Ed.) Learning about Corporate Social Responsibility; The Dutch experience, pp. 00-01? (Amsterdam: IOS press).

Loeber, A. (2004) Practical wisdom in the risk society. Methods and practice of interpretive analysis on questions of sustainable development, Thesis, University of Amsterdam, Amsterdam.

Meadows, D.H., Meadows, D.L., Randers, J. \& Behrens, W.W. (1972) The Limits to Growth. A Report for the Club of Rome's Project on the Predicament of Mankind (London: Earth Island).

Minsky, M. (1988). The Society of the Mind (New York: Simon \& Schuster).

Molnar, E. \& Mulvihill, P.R. (2003) Sustainability-focused Organizational Learning: Recent Experiences and New Challenges, Journal of Environmental Planning and Management, 46(2), pp. 167-176.

Revans, R. (1980) Action Learning. New Techniques for Action Learning (London: Blond \& Briggs).

Revans, R. (1982) What is action learning? Journal of Management Development, 1(3), pp. 64-75.

Roome, N. (2002) Referencing NIDO in an International Context. An inventory of national knowledge and innovation networks for sustainable development (Leeuwarden: NIDO). 
Senge, P., Kliener, A., Roberts, C., Ross, R., Roth, G. \& Smith, B. (1999) The Dance of Change: The Challenges of Sustaining Momentum in Learning Organizations (New York: Doubleday).

Schön, D.A. (1983) The Reflective Practitioner: How professionals think in action (New York: Basic Books).

Shelton, R. (1994) Hitting the Green Wall: Why Corporate Programs Get Stalled, Corporate Environmental Strategy, 2(2), pp. 00-01?.

Social and Economic Council (SER) (2001) Corporate Social Responsibility; A Dutch Approach (Assen: Van Gorcum).

Whitaker, G.P. (1980) Coproduction: citizen participation in service delivery, Public Administration Review, 40, pp. 240-246.

Williamson, O. E. (1991) Comparative Economic Organization: The Analysis of Discrete Structural Alternatives, The Administrative Science Quarterly, 36, pp. 269-296.

World Commission on Environment and Development (WCED) (1987) Our Common Future (New York and Oxford: Oxford University Press).

Zadek, S. (2001) The Civil Corporation. The New Economy of Corporate Citizenship (London and Sterling, VA: Earthscan Publications).

Zwetsloot, G. (2003) From Management Systems to Corporate Social Responsibility, Journal of Business Ethics, 44, pp. 2001-207. 


\section{CJOE200401}

Queries

Jacqueline Cramer \& Anne Loeber

Q1 Note 1. Friedman, 1962 - not in reference list. Please supply full details or delete.

Q2 Goldsmith, ? et al. - please supply initials of Goldsmith and names of other editors.

Q3 Loeber, A. (2003b) - please supply page numbers.

Q4 Shelton, R. (1994) - please supply page numbers.

Q5 Zwetsloot, G. (2003) - please check page numbers - pp. 2001-207. 